\title{
Validation of a Measuring Instrument to Ascertain the Effectiveness of Career Guidance Provided as Part of the Subject Life Orientation
}

\author{
Petronella Jonck \\ (PhD Psychology; Hons Industrial Psychology) \\ Deputy Director of Research and Policy Development, Department of Community Safety, Gauteng Government \\ Email: petrojonck@hotmail.com/Petronella.Jonck@Gauteng.gov.za
}

\section{Doi:10.5901/ajis.2014.v3n6p359}

\begin{abstract}
Evidence based policy development is currently underscored international. Specifically within the South African context it is of great concern that Life Orientation as part of Educational policy has been implemented without any clear indication of its efficacy. The article reports on the development and validation of a measuring instrument designed to quantitatively evaluate the effectiveness of career guidance received as part of the subject Life Orientation. The sample consisted out of 430 grade 10 respondents from the Mangaung area, the capital of the Free State province. A 25-item self-reporting instrument was utilized measuring service delivery, personal confidence, completion of personality inventories, subject satisfaction and knowledge of career path. The theoretical underpinning for the before mentioned questionnaire was the Social Cognitive Career Development Theory. Cronbach Alpha Coefficient was used to determine the reliability of the scale $(\alpha=0.86)$, followed by exploratory and confirmatory factor analysis. Exploratory factor analysis yielded a 6-factor solution, however parallel analysis and scree-test identified a 3-factor solution. Confirmatory factor analysis indicated that the 3-factor model was a good fit. It is recommended that the questionnaire be amended and tested in various other provinces and that results of various studies are used in educational policy development.
\end{abstract}

Keywords: Life Orientation, Career guidance services, Social Cognitive Career Development Theory, Exploratory Factor Analysis, Confirmatory Factor Analysis

\section{Introduction}

South Africa is faced with the conflicting task of rebuilding its workforce by means of an integrated education system, while at the same time, attempting to address prevailing unemployment (Perry 2009). As such career guidance has become increasingly important in facilitation of the match between supply and demand factors in the labour market, reducing unemployment and addressing prevailing social exclusion (Lundahl \& Nilsson, 2009). Singaravelu, White and Bringaze (2005) eluded to career guidance services which are typically a result of economic development in the sense that developing countries in the early stages of economic development direct individuals into professions that benefit the national economy. For that reason, the Organisation for Economic Co-operation and Development confirmed the need for countries to establish lifelong career guidance systems as part of active labour market policies (Watts 2010). Additionally, Dabula and Makura (2013) further noted that the necessity to expand career guidance interventions in educational settings is an international phenomenon ascribed to perceived economic and social benefits. Previous research indicated that lack of access to career guidance in diverse populations (Du Toit, 2005; Bernes, Bardick \& Orr 2007), lack of academic preparation (Van Schalkwyk, 2007) and lack of career guidance in secondary schools infringe on skills development after completion of secondary education (Dabula \& Makura, 2013) underscoring the importance of career guidance services for economic development.

In accordance with emerging international trends concerning the incorporation of career guidance into the core curriculum (Hue, 2008), career guidance within the South African context is a component of the National Curriculum Statement (CAPS) as part of the subjects Life Orientation (Vambe, 2005). The pedagogical interface underscoring Life Orientation can be categorised as part of the Life Skills faction, which is currently prevalent in many countries and often propagated in educational settings (Jacobs, 2011). Despite the incorporation of career guidance services in the core curriculum, Dabula and Makura (2013) indicated that in South Africa, career choices and by extension subject choices are accidental, rushed decisions imposed by external forces and the status quo which highlights the need to interrogate career guidance practises in secondary schools. 
A paucity of research studies could be found that investigate the effectiveness of the subject Life Orientation in general, not to mention with specific reference to career guidance as component of Life Orientation. As indicated by Jabobs (2011) even though some research assume, to an extent, that Life Orientation is effective, little empirical evidence could be found to support such claims. Furthermore, effectiveness becomes even more questionable when facilitators of the subject Life Orientation often receive minute formal training (Rooth, 2005). Van Deventer (2009) noted that Life Orientation is taught by a variety of facilitators who lack specialisation in this field adversely impacting the effectiveness thereof ascribed to the fact that the epistemology and skills of the teacher determine the status and practise of the subject. A study done by Howieson and Semple (2001) in Scotland indicated that various methods can be used to measure the effectiveness of career guidance services provided at secondary school level namely quantitative monitoring of activities, client and stakeholder feedback, learning outcomes measured, internal professional review, external review by governing bodies as well as longitudinal measures of impact. Internationally, quantitative monitoring of work activities and client feedback were most often used based on the model of self-evaluation (Howieson \& Semple, 2001). This however is not the case in South Africa where most inquiries into the effectiveness of Life Orientation focuses on internal professional review and qualitative client and stakeholder feedback.

In light of the above the primary aim of the research reported on in this paper was to develop a psychometric stable quantitative measuring instrument to determine the effectiveness of specifically career guidance received as part of the subject Life Orientation based on the model of self-evaluation. The broad aim was divided into the following (a) developing and piloting a measuring scale to test the effectiveness of career guidance provided as part of the subject Life Orientation which specifically focused on client feedback, (b) provide initial psychometric information on the measure and (c) test its factor structure by means of factor analysis.

\section{Theoretical Underpinning}

The Social Cognitive Career Development Theory (SCCT) which is an extension of the Social Cognitive Theory by Bandura $(1997 ; 2001)$ is often used as theoretical framework in facilitation of the career decision-making process (Dabula \& Makura, 2013; Tang, Pan \& Newmeyer, 2008). The Social Cognitive Career Development Theory propositions that individual background and characteristics influence learning experiences and consequently self-efficacy. Self-efficacy in turn fosters interests and outcome expectations, which eventually determine career choice (Lent, Brown \& Hackett, 2000). Thus, individuals form enduring interests in an activity when they view themselves as competent and anticipate that performing it will produce valued outcomes (Brown, 2002). Dabula and Makura (2013) found in a South African study that learners' ability to make informed career choices was influenced by lack of self-knowledge or self-efficacy. Furthermore, it is asserted that aspects of the environment might have direct and moderating influences on career decision-making such as quality of educational experiences (Brown, 2002; Tang et al., 2008). In this regard Rottinghaus, Lindley, Green and Borgen (2002) found that learning environments have been proven to statistically significantly influence an individual's level of educational aspirations. Turner and Lapan (2002) found, and were later confirmed by Tang and colleagues (2008), that learning experiences, significantly influence self-efficacy, which then impact career interest and choices.

The Social Cognitive Career Development Theory was adjusted to underpin the questionnaire that was developed to measure grade 10 learners' perception of the effectiveness of career guidance received as part of the subject Life Orientation (see Figure 1). It was hypothesised that services provided as part of the subject Life Orientation, thus Learning Experiences, influence personal confidence (Self-efficacy) and subject satisfaction (Outcome Expectations), which in turn lead to career path knowledge or career interests and ultimately career choice. Last mentioned was not incorporated in this study ascribed to the fact that grade 10 learners were included in the sample and cannot meaningfully reflect on their career choices yet.

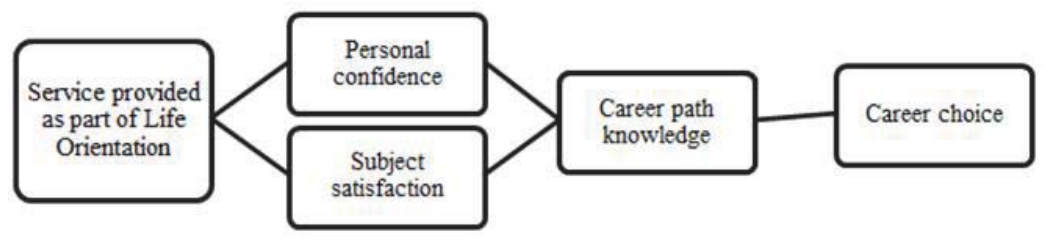

Figure 1: The conceptual model adapted from SCCT (Tang, et al., 2008: 287) 


\section{Development of 'The Effectiveness of Career Guidance Programmes at Secondary School Level - Learner Questionnaire'}

Constructing a measuring instrument to determine the effectiveness of career guidance provided as part of the subject Life Orientation took place in two phases. Phase one focused on scale development and subsumes item selection, and a pilot study to develop the initial scale. While, phase two emphasized testing the measuring instrument and determining the psychometric properties thereof.

\subsection{Development of item pool}

Phase one which focused on item selection and initial piloting of the measuring instrument commenced with a literature review specifically focusing on the aspects of career guidance that are supposed to be included in the Life Orientation curriculum. After various items were selected a focus group interview were held to evaluate the clarity and plenitude of the items selected. After careful consideration of the feedback from the focus group interview the number of items was reduced and language editing occurred to enhance respondents understanding of the content of the questions. Successively, a sample was drawn to initiate the pilot study.

\subsection{Participants of pilot study}

The sample consisted out of 30 respondents in total $(n=30)$ from two secondary schools in the Mangaung area. A brief synopsis of the composition of the pilot study sample indicated that 16 male and 14 female respondents were included, 16 respondents were from School A and 14 respondents from School B. Additionally, 6 respondents reported that Afrikaans were their mother tongue, while 11 respondents were English speaking and 13 respondents used an Indigenous Language as their home language. The pilot study sample was representative of the sample used in the main study.

\subsection{Initial psychometric properties}

The measuring scale after item selection was submitted to 3 grade 10 learners and their legal guardians to determine whether the items were clear, comprehendible and pitched on their cognitive level referring to face validity. Moreover, professional Life Orientation teachers who had experience in facilitating the subject Life Orientation were requested to provide insight into the content of the selected items. Thus content validity was investigated. Cronbach's Alpha Coefficient was performed to test the reliability of the questionnaire as a whole as well as for the individual items. The Cronbach a estimates for the total scale was 0.86 standardised. Table 1 below provide the Cronbach a estimates for the individual scale items. As can be seen from Table 1below all the scale items had an Alpha coefficiency between 0.84 and 0.87. The reliability data in addition to the validity were promising and consequently based on the results of the pilot study the measuring instrument was used in the main research study to determine the effectiveness of career guidance as component of the subject Life Orientation.

Table 1: Reliability results for the individual questionnaire items

\begin{tabular}{|c|c|c|c|c|}
\hline \multirow{2}{*}{$\begin{array}{c}\text { Deleted } \\
\text { Variable }\end{array}$} & \multicolumn{2}{|c|}{ Raw Variables } & \multicolumn{2}{c|}{ Standardized Variables } \\
\cline { 2 - 5 } & $\begin{array}{c}\text { Correlation } \\
\text { with Total }\end{array}$ & Alpha & $\begin{array}{c}\text { Correlation } \\
\text { with Total }\end{array}$ & Alpha \\
\hline Ques1 & 0.326588 & 0.851075 & 0.333444 & 0.853012 \\
\hline Ques2 & 0.093331 & 0.857803 & 0.099931 & 0.860405 \\
\hline Ques3 & 0.088375 & 0.855376 & 0.089510 & 0.860728 \\
\hline Ques4 & 0.510574 & 0.844655 & 0.504946 & 0.847396 \\
\hline Quest5 & 0.323589 & 0.852153 & 0.328024 & 0.853187 \\
\hline Ques6 & 0.353091 & 0.850412 & 0.360247 & 0.852145 \\
\hline Ques7 & 0.629752 & 0.841815 & 0.628698 & 0.843243 \\
\hline Ques8 & 0.330650 & 0.850909 & 0.341308 & 0.852758 \\
\hline Ques9 & 0.420117 & 0.848134 & 0.390009 & 0.851178 \\
\hline Ques10 & 0.542830 & 0.844589 & 0.568915 & 0.845260 \\
\hline
\end{tabular}




\begin{tabular}{|c|c|c|c|c|}
\hline \multirow{2}{*}{$\begin{array}{l}\text { Deleted } \\
\text { Variable }\end{array}$} & \multicolumn{2}{|c|}{ Raw Variables } & \multicolumn{2}{|c|}{ Standardized Variables } \\
\hline & $\begin{array}{l}\text { Correlation } \\
\text { with Total }\end{array}$ & Alpha & $\begin{array}{l}\text { Correlation } \\
\text { with Total }\end{array}$ & Alpha \\
\hline Ques11 & 0.467705 & 0.846731 & 0.465130 & 0.848714 \\
\hline Ques12 & -.025229 & 0.867108 & 0.000282 & 0.863472 \\
\hline Ques13 & 0.597498 & 0.842659 & 0.591635 & 0.844496 \\
\hline Ques14 & 0.560744 & 0.842833 & 0.560945 & 0.845527 \\
\hline Ques15 & 0.446861 & 0.847166 & 0.433947 & 0.849740 \\
\hline Ques16 & 0.478095 & 0.846358 & 0.468786 & 0.848593 \\
\hline Ques17 & 0.667835 & 0.840044 & 0.665654 & 0.841986 \\
\hline Ques18 & 0.658692 & 0.840698 & 0.657618 & 0.842260 \\
\hline Ques19 & 0.374318 & 0.849691 & 0.359723 & 0.852162 \\
\hline Ques20 & 0.581145 & 0.841877 & 0.571220 & 0.845182 \\
\hline Ques21 & 0.506536 & 0.845624 & 0.506712 & 0.847337 \\
\hline Ques22 & 0.498281 & 0.845314 & 0.493835 & 0.847765 \\
\hline Ques23 & 0.214602 & 0.854772 & 0.222695 & 0.856554 \\
\hline Ques24 & 0.235663 & 0.854602 & 0.246406 & 0.855802 \\
\hline Ques25 & 0.284711 & 0.852084 & 0.278881 & 0.854766 \\
\hline
\end{tabular}

\section{Methods}

\subsection{Participants and procedure}

The sample consisted out of $430(n=430)$ grade 10 learners from 7 randomly selected secondary schools in the Free State Province specifically the Mangaung area which is the capital of the Free State Province. Once a list of all the secondary schools in the area was obtained sampling took place by including every fifth school. Not all the schools that were initially selected and approached opted to participate in the research study. After Institutional Review Board approval for the study were gained at each secondary school the questionnaires were handed out indicative of convenient sampling. The final sample consisted out of 430 respondents which are on the 95 confidence level representative of the population with a 5\% margin of error. Since the research study focused on grade 10 learners the majority of the sample $(n=388 ; 90.4 \%)$ were between $15-17$ years of age. The average age of the sample was $\bar{x}=$ 15.2 years with a standard deviation of 0.309 . The gender distribution was skewed towards female respondents with $63.9 \%(n=274)$ female and $36.1 \%(n=155)$ male respondents. With reference to home language $54.7 \%(n=233)$ of respondents identified themselves as Afrikaans speaking (which might include both white and coloured respondents), $38.4 \%(n=165)$ spoke an Indigenous language and $7 \%(n=30)$ spoke English first language. The language distribution was in accordance with the racial distribution of the population. Taking the type of school into consideration especially in light of South Africa's history of racial segregation 39.8\% $(n=171)$ of the respondents came from previously and predominantly white schools, $47.4 \%(n=204)$ from predominantly black schools and $12.8 \%(n=55)$ from predominantly coloured schools. These schools were also located in previously segregated geographical areas.

\subsection{Data collection instrument}

The effectiveness of career guidance at secondary school level - learners questionnaire is a 25 item self-reporting instrument covering five categories on a four point Likert-type scale of 1 (Always / Very confident / Strongly agree) to 4 (Never / No confidence / Strongly disagree). The categories covered include service delivery or educational experiences (e.g. My life orientation teacher teaches us study methods to study more effectively), personal confidence (e.g. I am confident that I will be able to choose a study field from a list of potential study fields that I am considering), completion of personality inventories (e.g. I have done a personality versus job questionnaire), overall knowledge of career path (e.g. I know what I want to do after school) and overall satisfaction with subject choices (e.g. I have chosen the correct subjects). The aspects measured are in accordance with the Social Cognitive Career Development Theory that was discussed in the previous section. The theoretical range of scores is $25-100$. The measuring instrument also included a page to collect demographic information such as age, gender, home language, socio-economic status and type of school. The final section included five open-ended questions where learners were required to motivate their answers using narratives for example "How would you describe the guidance you received from your life orientation teacher?" and "In 
what way has the help of your life orientation teacher influenced the subjects you have chosen?" The measuring instrument is available from the corresponding author upon request.

\subsection{Statistical analysis}

To determine the reliability of the questionnaire Cronbach's Alpha Coefficient was used on individual scale items and the total scale. To investigate the validity of the questionnaire exploratory, parallel and confirmatory factor analysis were conducted.

\subsection{Ethical clearance}

Ethical clearance was obtained on various levels ascribed to the fact that the research study included minors. Permission for the study was obtained from the Faculty Research Committee at the higher education institution where the researcher was based, after which the study was registered with the Department of Education in the Free State Province. After permission was obtained from the principle and Institutional Review Board of individual secondary schools consent forms were handed out to participants and their legal guardians. Participants and their legal guardians were informed of the voluntary nature of participation, and their rights to withdraw from the study at any juncture. All participants and legal guardians provided written informed consent and permission to report findings.

\section{Results}

\subsection{Psychometric properties of scale}

The total scale had a Cronbach Alpha Coefficient of 0.856 with a scale mean of 53.66 and a standard deviation of 10.367 . In order to determine the factorability of the scale and to determine whether the data adhere to the basic assumptions thereof an inter-correlation between the subscales or factors were determined and illustrated in Table 2. As can be seen from Table 2 the a estimates for the various subscales ranged from 0.806 to 0.857 . The 5 subscales statistically significantly correlated with each other indicating the suitability of data for factor analysis.

Table 2: Scale descriptive statistics, Alpha reliabilities coefficients and inter-correlations

\begin{tabular}{|c|c|c|c|c|c|c|c|c|}
\hline \multirow{2}{*}{ Subscale } & \multirow{2}{*}{$\overline{\boldsymbol{x}}$} & \multirow{2}{*}{ std } & \multirow{2}{*}{$\boldsymbol{\alpha}$} & \multicolumn{5}{|c|}{ Inter-correlation matrix } \\
\cline { 5 - 9 } & & & SD & PC & PI & CP & SS \\
\hline SD & 2.50 & 0.549 & 0.806 & 1 & & & & \\
\hline PC & 1.82 & 0.474 & 0.809 & $0.390^{\star \star}$ & 1 & & & \\
\hline PI & 2.19 & 0.855 & 0.857 & $0.162^{\star \star}$ & $0.202^{\star \star}$ & 1 & & \\
\hline CP & 1.71 & 0.877 & 0.856 & $0.205^{\star \star}$ & $0.459^{\star \star}$ & $0.220^{\star \star}$ & 1 & \\
\hline SS & 1.60 & 0.720 & 0.854 & 0.042 & $0.310^{\star \star}$ & $0.180^{\star \star}$ & $0.430^{\star \star}$ & 1 \\
\hline
\end{tabular}

${ }^{\star \star} \mathrm{p} \leq 0.01$ Note: SD = Service Delivery; PC = Personal Confidence; PI = personality inventories; CP = Career Path Knowledge; SS = Subject Satisfaction.

\subsection{Exploratory factor analysis}

The data were factorable with Kaiser-Meyer-Olkin measure of sampling at 0.864 and Bartlett's Test of Sphericity; $x^{2}=$ $2704.043, d f=300$ and $p \leq 0.000$. An exploratory factor analysis with oblique (Oblimin) rotation was used based on results of the correlation matrix shown in Table 2 which indicated that the subscales were interrelated. Six components had an eigenvalue exceeding 1 and accounted for 53.898\% of the total variance. The six components explained $22.908 \%, 10.284 \%, 6.825 \%, 5.141 \%, 4.533 \%$ and $4.207 \%$ of the variance respectively. The pattern matrix is tabulated in Table 3. 
Table 3: Exploratory factor analysis results for a 6 factor solution pattern matrix

\begin{tabular}{|c|c|c|c|c|c|c|}
\hline \multirow{2}{*}{ Questions } & \multicolumn{6}{|c|}{ Component } \\
\hline & 1 & 2 & 3 & 4 & 5 & 6 \\
\hline PC3 & 0.672 & & & & & \\
\hline PC4 & 0.501 & & & 0.427 & & \\
\hline PI1 & -0.445 & & & 0.352 & & \\
\hline SD5 & & 0.828 & & & & \\
\hline SD4 & & 0.772 & & & & \\
\hline SD7 & & 0.728 & & & & \\
\hline SD6 & & 0.709 & & & & \\
\hline SD9 & & 0.446 & & & & \\
\hline PC6 & & & & & & \\
\hline SD12 & & & 0.778 & & & \\
\hline SD11 & & & 0.654 & & & \\
\hline SD10 & & & 0.627 & & & \\
\hline SS1 & & & & 0.789 & & \\
\hline CP1 & & & & 0.733 & & \\
\hline PC1 & & & & 0.473 & & \\
\hline SD2 & & & & & -0.799 & \\
\hline SD3 & & & & & -0.713 & \\
\hline SD8 & & & & & -0.556 & \\
\hline SD1 & & 0.428 & & & -0.440 & \\
\hline PC10 & & & & & & 0.843 \\
\hline PC8 & & & & & & 0.680 \\
\hline PC2 & & & & & & 0.575 \\
\hline PC9 & & & & & & 0.529 \\
\hline PC8 & & & & & & 0.415 \\
\hline PC5 & & & & 0.337 & & 0.353 \\
\hline
\end{tabular}

Note: SD = Service Delivery; PC = Personal Confidence; PI = personality inventories; $C P$ = Career Path Knowledge; SS = Subject Satisfaction. Cut-off values were set at 0.3 (Pallant, 2011).

However, an inspection of the scree plot indicated a clear break after the third factor. Consequently, based on the screetest, it was decided to retain three components for further investigation. This was supported by the results of the Monte Carlo Parallel Analysis, which indicated that only three components had eigenvalues exceeding the corresponding criterion values for a randomly generated data matrix of the same size ( 25 variables $\times 430$ respondents). Confirmatory factor analysis was done with a forced 3 factor rotation with results displayed in Table 4 below.

Table 4: Three factor component matrix solution

\begin{tabular}{|c|c|c|c|}
\hline \multirow{2}{*}{ Scale Item } & \multicolumn{3}{|c|}{ Component } \\
\hline & 1 & 2 & 3 \\
\hline PC8 - confidence in preparing a good cV & 0.610 & -0.307 & \\
\hline SD7 - cope with exam stress & 0.586 & & \\
\hline SD5 - effective use of time and exam preparation & 0.562 & 0.328 & -0.452 \\
\hline PC6 - confidence to determine work values & 0.559 & & \\
\hline SD9 - insight into strengths and weaknesses & 0.556 & & \\
\hline SD4 - use of study methods & 0.546 & 0.311 & -0.300 \\
\hline PC5 - confidence to gain desired employment & 0.544 & -0.334 & \\
\hline PC4 - confidence in job interest fit & 0.541 & -0.380 & \\
\hline SD6 - motivation to study and positive attitude & 0.537 & 0.338 & \\
\hline PC2 - confidence in study course selection & 0.526 & & \\
\hline CP1 - overall career path knowledge & 0.504 & -0.363 & \\
\hline SD1 - availability of jobs and subjects to match & 0.503 & 0.328 & \\
\hline PC7 - confidence to determine financial aspects & 0.499 & -0.310 & \\
\hline PC9 - confidence to identify relevant stakeholders & 0.497 & -0.373 & \\
\hline
\end{tabular}




\begin{tabular}{|c|c|c|c|}
\hline \multirow{2}{*}{ Scale Item } & \multicolumn{3}{|c|}{ Component } \\
\hline & 1 & 2 & 3 \\
\hline PC1 - confidence to do a relevant internet search & 0.487 & & \\
\hline SD8 - instruction to look and apply for a job & 0.471 & 0.437 & \\
\hline PC10 - confidence to develop contingency plan & 0.433 & & \\
\hline SD2 - individual attention from LO teacher & 0.407 & 0.400 & \\
\hline PC3 - confidence in aptitude & 0.407 & & \\
\hline SD3 - discussion with legal guardian & 0.322 & & \\
\hline PI1 - completion of personality inventories & & & \\
\hline SS1 - overall subject satisfaction & & -0.439 & \\
\hline SD12 - Internet access at school & & & 0.592 \\
\hline SD10 - access to career related material & 0.415 & 0.327 & \\
\hline SD11 - access to higher educational information & 0.419 & 0.373 & 0.497 \\
\hline
\end{tabular}

Note: SD = Service Delivery; $\mathrm{PC}$ = Personal Confidence; $\mathrm{PI}$ = personality inventories; $\mathrm{CP}=$ Career Path Knowledge; SS = Subject Satisfaction.

In pursuant to the results of the confirmatory factor analysis illustrated in Table 4 three underlying dimensions of effective career guidance as perceived by grade 10 learners were identified. The following three factors were derived: overall career guidance and counselling (Factor 1), job specific guidance (Factor 2) and complementary service delivery (Factor 3). Factor 1 which underscores all aspects of career guidance and counselling included aspects relating to the preparation of a good cv, coping with examination stress, subject selection and various other aspects. Personal confidence in preparing a respectable curriculum vitae was the item with the highest factor loading $(0.610)$, followed by coping with examination stress (0.586) and instructions on the effective use of time (0.562). The item with the lowest factor loading was discussions with the legal guardians by Life Orientation teachers $(0.322)$, followed by individual attention from the Life Orientation teacher (0.407) and personal confidence in aptitude (0.407). Factor 2 focused more on jobs per se with items subsuming how to look for a job, availability of specific jobs and which subjects to take to pursue them, and personal confidence in job personality fit. The highest factor loading was for individual attention from the Life Orientation teacher (0.400). Factor 3 centred more around supplementary services provided as part of overall career guidance and counselling such as internet access at school, access to information regarding difference institutions of higher education, the use of time tables and study methods. The highest factor loading was for access to the internet (0.592). The item on completion of personality inventories did not load on to any of the factors and it is suggested that it be omitted in further investigations.

\subsection{Confirmatory factor analysis}

To further extend analysis of the validity of the measuring instrument, the scale was subjected to a confirmatory factor analysis. The model was tested using maximum likelihood and robust statistics. According to the recommendations by Mcllveen, Burton and Beccaria (2013) a good fit model has a $x^{2} /(\mathrm{df})<3$; comparative fit index $>0.95$, and a root mean square error of approximation 0.05 . The three-factor career guidance effectiveness measuring scale represented a good fit with $X^{2}=447.445 ; p \leq 0.000\left(X^{2} /(\mathrm{df})=1.962\right)$ and root mean square error of approximation of 0.0473108 . The goodness-fit indicators for various iterations are displayed in Table 5 below.

Table 5: Goodness-of-fit indicators of models

\begin{tabular}{|l|c|c|c|c|}
\hline Model & $\chi^{2}$ & df & $\mathbf{p}$ & $\mathbf{X}^{2}$ diff \\
\hline Single factor & 1211.761 & 275 & $0.000^{* \star}$ & \\
\hline Two factor & 689.869 & 251 & $0.000^{\star \star}$ & 521.892 \\
\hline Three factors & 447.445 & 228 & $0.000^{\star \star}$ & 242.424 \\
\hline
\end{tabular}

$$
* \star p \leq 0.01
$$

\section{Discussion of Results}

This study sought to develop a measuring instrument to determine the effectiveness of career guidance received as part of the subject Life Orientation. The development of the measuring instrument was underpinned by the Social Cognitive Career Development Theory (SCCT). The applicability of the SCCT to elucidate career and subject choice behaviour of 
secondary school learners have been verified on various occasions internationally (Tang et al., 2008; Turner \& Lapan, 2002). Nationally, Dabula and Makura (2013) utilized the SCCT as theoretical underpinning in their study on high school students' perception of career guidance. However, a qualitative research design was used in the previously mentioned study. As far as could be established no quantitative research could be found to verify the use of the SCCT in the South African context. Exploratory factor analysis performed supported a six-factor solution accounting for $54 \%$ of the total variance. Parallel analysis and the scree-test suggested a three-factor solution which was supported by confirmatory factor analysis. Factor one accounting for $23 \%$ of the total variance underscored all aspects related to career guidance in general. Factor Two accounting for $10 \%$ of the variance focused on job related guidance, while Factor Three accounting for $7 \%$ of the variance underscored supplementary assistance. Maximum likelihood and robust statistics indicated that the model was a good fit. Only one question did not load onto any of the factors and was related to the completion of personality inventories which was expected since the completion of personality inventories should not be included in the curriculum. In future it is suggested that this question be excluded from the measuring instrument. Based on the results, the SCCT model and the measuring instrument appeared to explain the interrelationship between services provided as part of the subject Life Orientation (Learning Experiences), career related personal confidence (Career Self-efficacy), subject satisfaction (Outcome Expectations), and knowledge of career path or career interests. Consequently, it is useful in understanding secondary school learners' career development processes and the quality of the career guidance related services provided as part of the subject Life Orientation. The findings of the study support those by Tang et al. (2008).

\section{Limitations}

Stakeholder or client feedback provides a measure of the perception of the appropriateness and value of the services received with a certain amount of bias. It is important to note that grade 10 learners' demand for career guidance services is not identical to their career guidance needs (Howieson \& Semple, 2001). It should also be taken into consideration that the research reported on in this paper was an initial investigation to develop an appropriate quantitative measuring instrument. Consequently, sampling took place in one province and caution is advised when making generalisations to the rest of South Africa.

\section{Conclusion and Recommendations}

Determining the effectiveness of interventions such as career guidance provided as part of the subject Life Orientation is an integral part of program management and has been mentioned as a top priority in various research studies conducted internationally and locally. The question remains nonetheless how to determine the effectiveness of career guidance services provided in the South African context. The majority of researchers call for qualitative methodologies however these type of methodologies are exploratory with findings that cannot be generalized to the wider population. The research reported on in this paper aimed to develop and validate a quantitative measuring instrument that will generate client feedback that can be statistically analysed to inform and shape social and public policies, contribute to national lifelong learning and skills development, employability as well as addressing social inequalities based on gender, race and education. Against this background it is recommended that the research results of this study be used as a base to further improve the measuring instrument by deleting items that did not load unto the three factors mentioned, extend the use of the scale in different regions and creating a platform to perform meta-analysis. Meta-analysis of both quantitative and qualitative research results could prove valuable in ascertaining whether or not the aims and objectives of the programme intervention, Life Orientation with specific reference to career guidance have been reached.

\section{References}

Bandura, A. (1997). Self-efficacy: The exercise of control. New York: W.H. Freeman.

Bandura, A. (2001). Social Cognitive Theory: An agentic perspective. Annual Psychology Review, 52, 1-26.

Bernes, K.B., Bardick, A.D., \& Orr, D.T. (2007). Career guidance and counselling efficacy studies: An international research agenda. International Journal of Education and Vocational Guidance, 7, 81-96.

Brown, D. (2002). Career choice and development (4th ed.). San Francisco, CA: Jossey-Bass.

Dabula, P., \& Makura, A.H. (2013). High school student's perception of career guidance and development programmes for University access. International Journal for Educational Science, 5(2), 89-97.

Du Toit, A. (2005). A review of Labour Markets in South Africa: career guidance and employability service. Pretoria: Human Sciences 
Research Council.

Howieson, C., \& Semple, S. (2001). How would you know? Assessing the effectiveness of career guidance services. CES briefings, Scotland.

Jacobs, A. (2011). Life Orientation as experienced by learners: a qualitative study in North-West Province. South African Journal of Education, 31, 212-223.

Lent, R.W., Brown, S.D., \& Hackett, G. (2000). Contextual support and barriers to career choice: A social cognitive analysis. Journal of Counselling Psychology, 47, 36-49.

Lundahl, I., \& Nilsson, G. (2009). Architects of their own future? Swedish career guidance policies. British Journal of Guidance and Counselling, 37(10), 27-38.

Mcllveen, P., Burton, L.J., \& Beccaria, G. (2013). A short form of the career futures inventory. Journal of Career Assessment, $21(1), 127-$ 138.

Pallant, J. (2011). SPSS survival manual: A step by step guide to data analysis using SPSS (4th ed.). NSW, Australia: Allen \& Unwin.

Perry, J.C. (2009). Career counselling with secondary school-aged youth: Direction for theory, research and practice. South African Journal for Higher Education, 23(2), 282-504.

Tang, M., Pan, W., \& Newmeyer, M.D. (2008). Factors influencing high school students' career aspirations. American School Counsellor Association, 11(5), 285-295.

Turner, S., \& Lapan, R.T. (2002). Career self-efficacy and perception of parent support in adolescent career development. Career Development Quarterly, 51, 44-55.

Rooth, E. (2005). An investigation of the status and practise of Life Orientation in South African schools in two provinces. Unpublished PhD Thesis, University of Cape Town, Cape Town.

Rottinghause, P., Lindley, L.D., Green, A., \& Borgen, F.H. (2002). Educational aspirations: The contribution of personality, self-efficacy and interests. Journal of Vocational Behaviour, 61, 1-19.

Singaravely, H.D., White, L.J., \& Bringaze, T.B. (2005). Factors influencing international students' career choice. Journal of Career Development, 32(1), 46-59.

Vambe, M.T. (2005). Opening and transforming South African Education. Open Learning, 20, 285-293.

Van Deventer, K. (2009). Perspectives of teachers on the implementation of Life Orientation in grades R-11 from Selected Western Cape Schools. South African Journal of Education, 29, 127-145.

Van Schalkwyk, S.C. (2007). Crossing discourse boundaries - students diverse realities when negotiating entry into knowledge communities. South African Journal of Higher Education, 21, 596-609.

Watts, A.G. (2010). National all-age career guidance services: evidence and issues. British Journal of Guidance and Counselling, 38(1), 31-44. 
